REVISTA DE DERECHO UNED, NÚM. 18, 2016

\title{
EL ESCORIAL, IDEADO Y CONSTRUIDO POR EL JUSTINIANO IBÉRICO
}

\author{
EL ESCORIAL, DEVISED AND BUILT \\ BY THE IBERIAN JUSTINIAN
}

\author{
Ramón J. Fernández de Marcos Morales ${ }^{1}$ \\ Académico C. de la RAJYL. \\ Profesor Doctor Asociado de la UNED
}

Resumen: Partiendo de la premisa de que el reinado de Felipe II se caracterizó por un enorme poder político-religioso y de que su obra El Escorial ha sido comparada con el Templo de Salomón, y de que el mismo monarca ha sido denominado como el nuevo Salomón o Salomón II, el Autor se cuestiona acerca de la relevancia jurídica de su reinado, máxime cuando una parte de la doctrina le ha considerado el Justiniano ibérico.

Abstract: Based on the premise that reign of Philip II characterized for an enormous political-religious power, and that his work El Escorial has been compared with de Temple of Solomon, and that the same monarch has been named as the new Solomon or Solomon II, the Author raises about issues legal relevance of his reign, especially when part of doctrine has been considered the Iberian Justinian.

Palabras clave: Felipe II. Justiniano. Salomón. El Escorial. El Templo de Jerusalén.

Keywords: Philip II. Justinian. Solomon. El Escorial. The Temple of Jerusalem.

Recepción original: 15/02/2016

Aceptación original: 6/04/2016

${ }^{1}$ Dedico este artículo a mi nieto Javier, que me mostró el Salón de Batallas.

(C) UNED. Revista de Derecho UNED, núm. 18, 2016 
Sumario: 1. Introducción. Felipe II y El Escorial. 2. El Escorial y el Templo de Salomón. 3. Felipe II, el Justiniano ibérico. 4. A modo de conclusión.

\section{INTRODUCCIÓN. FELIPE II Y EL ESCORIAL}

«Apenas hay quien se llegue a visitar El Escorial con ánimo desprevenido y sereno, a recibir la impresión de una obra de arte, a gozar, con el goce más refinado y raro cual es la contemplación del desnudo arquitectónico. Casi todos los que a ver El Escorial se llegan, van con anteojeras, con prejuicios políticos o religiosos, ya en un sentido ya en el contrario; van más que como peregrinos del arte, como progresistas o como tradicionalistas, como católicos o como librepensadores. Van a buscar la sombra de Felipe II, mal conocido y peor comprendido, y si no se la encuentran se la fingen.»

Estas palabras de Miguel de Unamuno, nos introducen en la búsqueda de «la sombra» de Felipe II, de quien desde ya adelanto que una característica fundamental de la personalidad del Rey Prudente fue su profundo sentimiento católico, hasta el punto de que afirmaba: «Prefiero no reinar, a reinar sobre herejes».

Partiendo de la premisa de que su reinado se caracterizó por un enorme poder político-religioso y de que su obra, El Escorial, ha motivado que, desde el principio, se le haya comparado con el rey Salomón, llegando algunos incluso a llamarle, como Lope de Vega, el nuevo Salomón, o Salomón II, como Góngora, me pregunto acerca de la relevancia jurídica de su reinado, máxime cuando parte de la doctrina le ha considerado el Justiniano ibérico.

El Escorial es un Panteón y una Basílica envueltos por un Monasterio y un Palacio, cerrados finalmente por una Biblioteca. Su población dejó de depender de Segovia, mediante real cédula de 1565, pasando a ser territorio de realengo y en el orden eclesiástico, Felipe II consiguió que se desvinculara del poderoso Arzobispado de Toledo y pasara a depender del Prior, mediante dos bulas papales de 1585 y 1586. En sus inmediaciones se construyeron la Casa de los Doctores, proyectada en 1583, las Casas de los Oficios (concebidas -la primera y la segunda- de forma unitaria), construidas entre 1587 y 1596, y los edificios de la Compaña, construidos entre 1590 y 1597.

La Biblioteca, fue unos de los mayores lugares de concentración del conocimiento, en el siglo XVI, con manuscritos árabes, armenios, chinos, griegos, hebreos, italianos, latinos, turcos, persas, entre otros 
muchos. Entre sus volúmenes se encuentran las Cantigas de Santa María de Alfonso X «el Sabio», el Libro de Horas de Isabel «la Católica», el Corán de Muley Zidán, la Biblia en hebreo de Arias Montano, el Códice Emilianense o una gran colección de incunables como la Civitas Dei de San Agustín, y otros tesoros bibliográficos, por lo que, aún hoy, es una de las mejores bibliotecas del mundo para el estudio de la Biblia.

La Casa de los Doctores, es la primera edificación que Juan de Herrera realiza fuera de El Escorial, se construyó para albergar a los Doctores y catedráticos en Teología y Arte, que no podían residir en el cenobio, por ser seglares.

Las dos primeras Casas de Oficios se hicieron para dar cobijo a los animales, que no podían estar en lugar sagrado, así como carruajes, utensilios de labranza y demás. Por cierto, que algunos autores han afirmado que las medidas de las Casas de Oficios se corresponden a las proporciones bíblicas del Arca de Noé, pero obviamente, no nos detendremos en este particular, por no ser objeto de nuestro estudio.

Los edificios de la Compaña, se construyeron para el servicio de la orden religiosa de los jerónimos, a quienes Felipe II encargó el cuidado y mantenimiento del monasterio, allí almacenaban sus útiles y daban cobijo a sus animales.

El Escorial, con sus más de 25 kilómetros de pasillos fue, en su época, lo que hoy conocemos como el centro de control de un Estado moderno. En total mide 207 x 161 metros, la cúpula de la Basílica tiene 92 metros de altura, los dos campanarios miden 72 metros, las cuatro torres de las esquinas miden 55 metros y consta de 4.000 habitaciones, 2.673 ventanas, 1.250 puertas, 45.000 libros imprimidos, 7.422 reliquias, 5.000 códices, 1.600 cuadros, 540 frescos, 232 libros de coro, 88 fuentes, 86 escaleras, 73 estatuas, 44 altares, 15 claustros, 13 oratorios, 11 aljibes, 9 órganos 9 torres, y 5 refectorios.

Cuando contemplamos El Escorial, inevitablemente nos preguntamos, por qué Felipe II ordenó su construcción y por qué se involucró personalmente en esta gigantesca obra. A mi juicio, en este punto, lo más certero es acudir a la Carta Fundacional firmada, el 22 de abril de 1567, por Felipe II, donde el rey nos manifiesta los dos motivos que le llevaron a la construcción de El Escorial:

Primero: «En agradecimiento por los muchos y grandes beneficios que Nos hemos recibido y recibimos diariamente de Nuestro Señor y porque él Nos ha guiado en Nuestras acciones en su santo 
servicio y ha conservado Nuestros imperios en su santa fe y en la religión por él instaurada...»

Segundo: «El Emperador y rey, Nuestro padre y señor, tras cedernos sus reinos, Nos encargó... según su última voluntad ocuparnos de su última morada y de la emperatriz Nuestra madre y señora, y siendo conscientes de la conveniencia de dar una sepultura muy digna a sus cadáveres y de que se les hagan ofrendas perpetuamente y de que se celebre su memoria; y porque Nos hemos decidido ser enterrados en el mismo lugar que ellos...».

Y añade: «Por estas consideraciones Nos fundamos y construimos el monasterio de San Lorenzo el Real en el pueblo Escorial de la diócesis de Toledo».

En definitiva, Felipe II ordena la construcción de El Escorial, para agradecer a Dios el mantenimiento de su imperio unido en la religión y dar una sepultura muy digna a su padre, a él mismo y a sus descendientes.

\section{EL ESCORIAL Y EL TEMPLO DE SALOMÓN}

Jerusalén ha tenido sólo dos Templos. El Templo del rey Salomón, construido entre 969 y 962 a. C., que sufrió diferentes profanaciones y fue destruido en el 586 a. C. y el Templo del rey Herodes el Grande, construido en el año 20 a. C., que restauró el Templo de Salomón, en el mismo lugar y respetando la planta física del edificio, pero ampliando patios y añadiendo muros exteriores. La destrucción de este Segundo Templo de Jerusalén fue profetizada por Jesucristo, para después de su muerte. Efectivamente, en el año 70 d. C., las legiones romanas destruyeron el Templo, desobedeciendo las órdenes del emperador Tito. Actualmente, sólo se conserva el muro occidental, conocido como el muro de las lamentaciones.

Felipe II después de acceder al trono, el 16 de enero de 1556, encargó al jesuita Juan Bautista Villalpando un estudio acerca del Templo de Salomón, porque quería construir una casa para Dios, Domus Dei, que fuera comparable con el Templo de Salomón, tomándose como modelo inicial la que, según la Biblia, había sido la mejor casa de Dios en la tierra, pero, como afirmó Chueca, ni la concepción de la obra por Felipe II, ni las trazas realizadas por Juan Bautista de Toledo o Juan Herrera, bastaron para crear El Escorial, ya que éste adquirió autonomía e impuso su propio camino. 
En este orden de cosas, hay que señalar que, lamentablemente, no se conservan la mayoría de las trazas que se realizaron de El Escorial, ya que se perdieron en el incendio del Alcázar en 1734, si bien se conserva algún rasguño en el manuscrito de la planta original del padre Sigüenza: «La planta primera trazada por Juan Bautista de Toledo hace poca diferencia de la de ahora, pero la montea se trocó mucho». Felipe II, eligió a Juan Bautista de Toledo, que había trabajado, desde 1546 hasta 1548, como ayudante de Miguel Angel en San Pedro del Vaticano, obra con la que tendría que competir en algunos aspectos. En este sentido, no extraña que, según las trazas del proyecto original que se conservan, se concibiera terminar El Escorial sin cerrar el atrio del Templo, quedando el Patio de Reyes abierto y al fondo la portada de la Basílica, significando así, de manera similar al Vaticano, que se acoge al peregrino en forma de abrazo, aunque finalmente se decidió cerrar el atrio, y situar la Biblioteca en el piso superior, así, en mi opinión, fue como si El Escorial hubiera adquirido vida propia.

Dibujo del autor
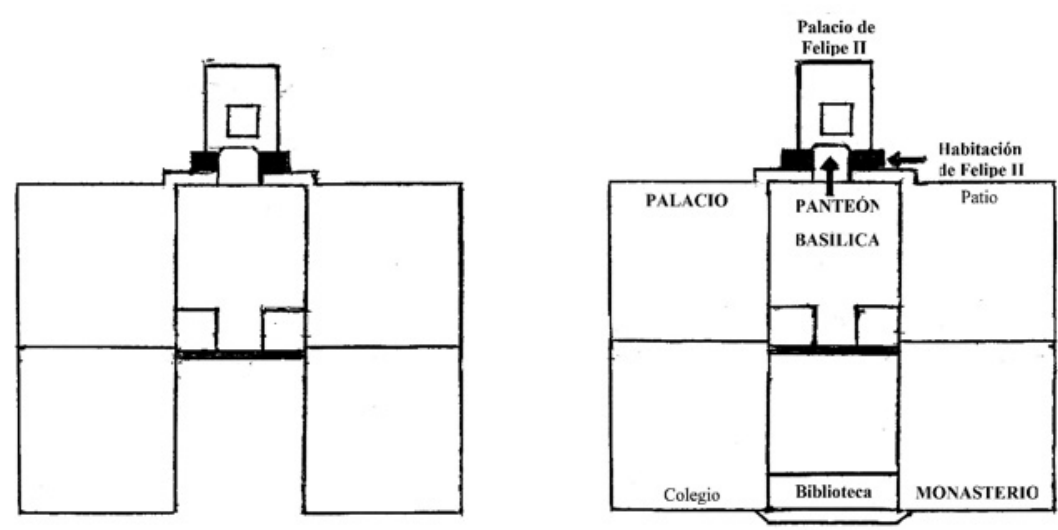

A la izquierda, idea inicial de El Escorial terminado, con el atrio del templo sin cerrar, según las trazas conservadas del proyecto original. A la derecha, El Escorial con la solución de Juan de Herrera, con el atrio cerrado y la Biblioteca en la planta superior.

Partiendo de las minuciosas descripciones del historiador judeoromano Flavio Josefo (37-101 d. C.), De la Cuadra, después de un completo y exhaustivo estudio de los múltiples tipos de codos, pies y varas de medir, afirma que tanto el Monasterio como el Palacio, tienen las mismas medidas que el Segundo Templo de Jerusalén, de forma que El Escorial duplica sus medidas, dejando en medio el Templo. Así el cronista y bibliotecario de El Escorial, el padre Sigüenza, 
escribió que: «El arquitecto Juan Bautista dividió finalmente el cuadro o cuadrángulo en tres partes principales, la del medio quedó para el Templo o entrada general».

Como es bien sabido, la traza del Templo realizada por Juan Bautista de Toledo, no se llevó a cabo, siendo diseñada finalmente por Juan de Herrera, siguiendo las trazas de Francesco Paccioto, y aunque no existe ninguna traza realizada por el italiano, si conservamos una carta manuscrita de su puño y letra, en la cual se atribuye el mérito de haber tenido la idea de hacer el Templo cuadrado, con preferencia a otra forma. No obstante, a pesar de la afirmación de Paccioto en la citada epístola, parece que lo que en realidad sucedió es que Paccioto supo interpretar acertadamente los deseos de Felipe II, así el padre Sigüenza afirmó que: «la planta cuadrada, no circular, del Templo, fue un invento de su dueño Felipe II».

Las tumbas de Carlos V y de Felipe II, fueron colocadas debajo de las estatuas del altar, y el Sancta Sanctorum, la zona más sagrada del Templo, el Altar de la Basílica, tenía debajo una modesta capilla redonda donde Felipe II quería que se colocaran las tumbas de la familia real, pero en el siglo XVII, los restos de Carlos V y Felipe II fueron trasladados de los llamados enterramientos a esta capilla, que se transformó en Panteón de Reyes. Algunos expertos, consideran este Panteón como el auténtico Sancta Sanctorum, por sus semejanzas con el Sancta Sanctorum de Salomón, por lo que intentan establecer su relación con la cúpula de la Roca, donde originariamente se encontraba el Sancta Sanctorum.

Por otra parte, al igual que en el rey Salomón, en el rey Felipe II, coinciden el poder político y el religioso, ya que después del Concilio de Trento, España jugó un papel fundamental ante los reformistas europeos, hasta el punto de que fue acusado de cesaropapismo al estilo anglosajón, ya que El Escorial sería el símbolo de la contrarreforma y del amplio poder que le otorgaba su vasto imperio, el lugar desde el que, mediante la fusión del Estado con la Iglesia, reinar sobre un territorio en el que jamás se ponía el sol. Así se entendería, como ha dicho un autor cuyo nombre no recuerdo, que el Palacio del Rey parece que está casi escondido, cuando la realidad es que está colocado en el centro de comunicaciones, como la cabina de un piloto que dirige una nave de gran poder.

En suma, El Escorial es un edificio que representa la unión del poder político-religioso de los Habsburgos españoles. Su ideación y construcción se inspiró en las referencias bíblicas del Templo de Salomón, cuyas medidas aún hoy desconocemos, por lo que no pue- 
de coincidir con el mismo, pero sí con el Templo de Herodes, al cual, como he dicho, duplica, dejando el Templo y el Panteón de Reyes en medio.

\section{FELIPE II, EL JUSTINIANO IBÉRICO}

Justiniano, cuando terminó de construir la iglesia de Santa Sofía de Constantinopla, pronunció la conocida frase de: «Salomón, te he vencido", queriendo significar que había superado el mítico templo de Jerusalén construido por Salomón.

En el año 532 d. C. Justiniano, a las pocas semanas de la destrucción de la Segunda Basílica de la época de Teodosio II (la primera era de la época de Constantino), ordenó que sobre los restos de las dos anteriores se construyera una Tercera Basílica (la que se conserva), de Santa Sofía de Constantinopla, igualmente dedicada a la Sabiduría divina, por eso quiso -al igual que el rey Salomón- un edificio que hubiera sido diseñado por Dios, pero que fuera más grande y majestuoso que sus dos predecesores. Así pues, parece que Justiniano, al igual que el rey Prudente, siguió la estela del rey Salomón.

Carlos V, viajó nueve veces a Alemania, siete a España, siete a Italia, cuatro a Francia, dos a Inglaterra y también a África, fue el emperador más brillante desde Carlomagno, quiso construir la república cristiana (lo que hoy denominamos Europa), por lo que se centró en gobernar Europa, utilizando para ello todos los recursos económicos y toda la tecnología militar a su alcance, lo que fue posible gracias a los fondos que venían de América (que pertenecía a Castilla) y que llegaban directamente a los puertos de Holanda, Génova o Alemania, sin pasar por España.

Como es sabido, Carlos V gobernó un amplio Imperio que, no obstante, nunca llegó a ser un Estado Unitario, lo único que llegaron a tener en común todos estos reinos, es el gobernante. Así como señala Brewer, la situación de Carlos V fue distinta en cada uno de sus dominios, pero con la importante salvedad de que los problemas que afectaban a algunos de ellos no necesariamente afectaban a otros, y con el añadido de que en cada uno de ellos tenía un título distinto, como Emperador del Sacro Imperio Romano, Rey de Castilla, Aragón y las dos Sicilias, Duque de Borgoña y Milán, o como Conde de Holanda, Flandes y Artois.

En este sentido, como sostiene Hugh Thomas, Carlos V estuvo más interesado en el futuro de Alemania y de Italia que en América, y 
terminó aceptando que los reyes fueran quienes decidieran la religión de sus territorios, por tratarse de una cuestión política, de manera que después de luchar por defender la dinastía de los Habsburgo y la religión católica, en 1556 al año de morir su madre, la reina Juana «la Loca», abdicó y dividió su imperio en dos: El imperio alemán, para su hermano Fernando I, que fue coronado Emperador del Sacro Imperio Romano Germánico el 24 de marzo de 1558 y que curiosamente había nacido en el Palacio Arzobispal, en Alcalá de Henares. Y los reinos españoles de la Península y las Indias, así como los Países Bajos, Nápoles y Milán, para su hijo Felipe II.

Así pues, el Rey Prudente heredó un imperio que incluía íntegramente el Continente Americano (conocido hasta el siglo XVIII como las Indias), el de mayor extensión geográfica, ya que, como recuerda Brewer, antes de que los ingleses o los franceses fundaran alguna colonia en América, Felipe II había ya consolidado las bases del Estado español con sus inmensas colonias americanas, toda vez que no fue hasta los diez años después de fallecer Felipe II en 1608, que Hudson navegó por la Isla de Manhattan, y veintidós años que los ingleses fundaron la colonia de Massachussets, en 1620.

Dibujo del autor

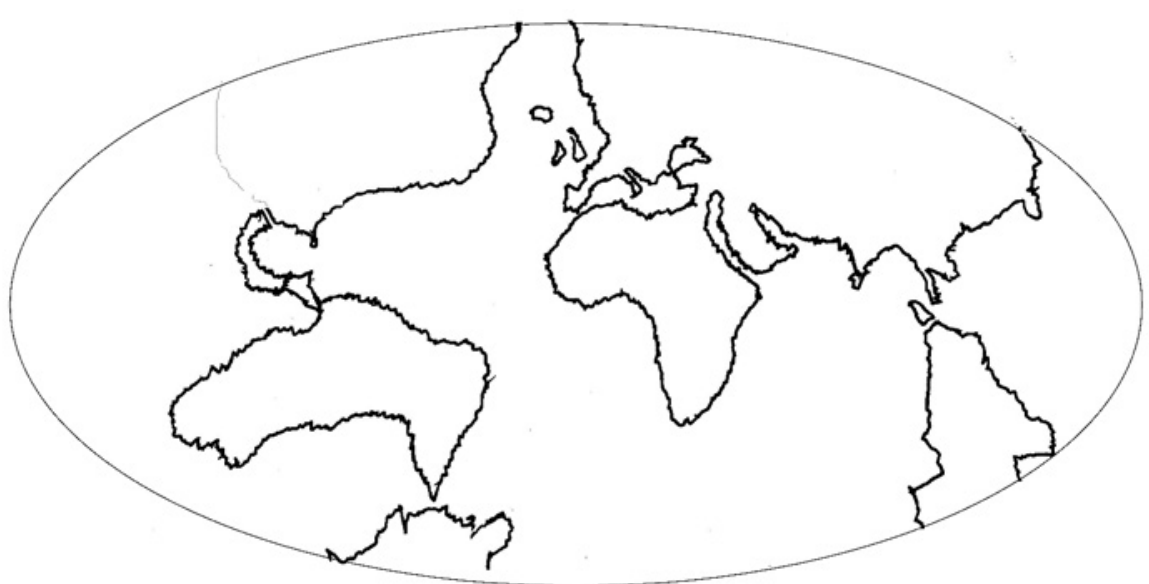

Mapa del mundo, en 1543. Sudamérica y Australia, aparecen fundidas en un solo subcontinente.

Al contrario que su padre, Felipe II apenas visitó sus territorios fuera de España, en parte para evitar las rebeliones comuneras a las que Carlos I de España, tuvo que enfrentarse y gestionó sus territorios, como las Indias, con virreyes y oficiales, convirtiendo a España 
en la primera Nación moderna, dotándola de infraestructuras, como casas de postas y posadas, con novedosas reformas administrativas, como el traslado de la corte a Madrid, convirtiéndola por primera vez, en la capital permanente de la monarquía española.

En relación con su labor de recopilación, hay que destacar que la primera línea recopiladora, comenzó con el codicilo de la reina Isabel en 1504, y fue llevada a cabo por Galíndez de Carvajal, que trabajó en paralelo en las Siete Partidas con Gregorio López, pero esta doble tarea de Carvajal quedará pérdida e inédita. La segunda línea recopiladora, comenzó con Carlos V cuando se comprometió a preparar la recopilación con las Cortes de Segovia en 1532, nombrando sucesivamente a tres recopiladores: Pedro López de Alcocer que trabajó hasta 1542, el doctor Diego Escudero que trabajó desde 1543 hasta su muerte en 1551, el licenciado Pedro López Arrieta que trabajó desde 1552 hasta su muerte en 1563.

Siguiendo la segunda línea recopiladora iniciada por su padre, Felipe II realizó un nombramiento decisivo: el licenciado Bartolomé de Atienza que trabajó desde 1563 hasta 1567, completando la labor de Arrieta y realizando el repaso y las correcciones finales. El Rey Prudente, entendió que la institución clave para la recopilación de leyes que regían en el Reino de Castilla, era el Consejo Real, por lo que le conminó para que cumplieran con dicho cometido y terminaran la Nueva Recopilación, sancionada por Felipe II en 1567. El texto, después de 34 años de trabajo, recogía íntegramente las Leyes de Toro y se convirtieron en el eje del Derecho español, resultando derecho común aplicable en la Corona de Castilla, reproduciendo también algunas de las disposiciones más importantes del Fuero Juzgo, del Fuero Real y del Ordenamiento de Alcalá. Recogían también lo más característico del Derecho español, con las pragmáticas y actos de Cortes, disposiciones legales éstas muy difíciles de encontrar, confirmándose nuevamente la vigencia general y supletoria de las Siete Partidas, de Alfonso X «el Sabio».

En este orden de cosas, como Fernández Rodríguez sintetiza de manera magistral: «el derecho romano preside, definitivamente, la base de su predominio, toda vez que al crearse un solo y fundamental texto legislativo se configura un aspecto unitario del Derecho nacional, con la consiguiente supresión de la dispersión hasta entonces existente, que dificultaba su conocimiento. Aparece un Derecho nacional más genuino, con la dignidad de un cuerpo de leyes, en volumen, extensión y autoridad histórica y tradicional comparable a la que había tenido el «Corpus iuris» romano. Con su base y apoyo los 
juristas españoles, afirmados en su Derecho tradicional, pueden hacer así una obra constructiva de importancia decisiva, poniendo al servicio de la práctica jurídica el armazón doctrinal de la concepción española del Derecho, lo que llevó a algún sector doctrinal a considerar a Felipe II, por esta obra, el Justiniano ibérico».

Pero Felipe II, no sólo monitorizó las primeras compilaciones de normas jurídicas vigentes en el reino de Castilla, sino también las dictadas desde Castilla para América, de forma que ordenó al Consejo de Indias recopilar toda la normativa indiana hasta entonces dispersa en Capitulaciones, Cédulas Reales, Instrucciones, Ordenanzas, desde sus comienzos. Proceso que culminó con las Ordenanzas sobre nuevos descubrimientos y poblaciones, aprobadas por Felipe II en el Bosque de Segovia el 13 de julio de 1573, en las que eliminaba el término «conquista», como título de adquisición de los descubrimientos, porque no quería dar ocasión para hacer agravios a los indios. En las Ordenanzas, también se regulaba por vez primera el proceso legal de poblamiento, que hasta la fecha se había hecho conforme a las Siete Partidas. De modo que las Ordenanzas, en palabras de Brewer, «marcan el punto culminante de la formulación jurídica en el proceso de poblamiento y de formación de ciudades en América latina».

En resumen, en la Nueva Recopilación (1567), elaborada para la Península Ibérica, y en las Ordenanzas sobre nuevos descubrimientos y poblaciones (1573), elaborada para los reinos de las Indias, encontramos otro rasgo fundamental en la personalidad de Felipe II: su faceta de legislador.

\section{A MODO DE CONCLUSIÓN}

Como sostiene Julián Marías, Felipe II es una figura enigmática, compleja y casi siempre desdibujada y, como recuerda González Palencia, asusta ver los millones de documentos de su reinado, leídos todos por él, anotados de su letra, hasta en las más nimias resoluciones; lo que, en mi opinión, resulta más sorprendente aún, si consideramos que, al final de sus días, ordenó que se quemaran todos sus documentos: "iQue se quemen los papeles!».

Acerca de por qué Felipe II ordenó la construcción de El Escorial y por qué se involucró de una forma tan personal en esta gigantesca obra, el mismo monarca, en la Carta Fundacional, nos dice que fue por dos motivos: para agradecer a Dios el mantenimiento de su imperio unido en la religión y para dar una sepultura muy digna a su padre, a él mismo y a sus descendientes. 
En relación con las medidas generales del Primer Templo de Jerusalén, el de Salomón, hay que señalar que no se conocen, pero sí las del Segundo Templo de Jerusalén, el de Herodes. Por el contrario, se sabe que ambos coincidían en las medidas del Santuario interior. Así pues, podemos establecer que no era posible reproducir el Templo de Salomón, pero sí que, partiendo de esta idea o modelo, como casa de Dios, El Escorial evolucionara según se iba construyendo, de manera que una vez terminados el Convento y el Palacio, el resultado final fue que se duplicaron las medidas del Templo de Herodes, dejando el Templo y el Panteón de Reyes en medio.

El Reino de España sentó las bases de un Estado moderno, superó la estructura del Sacro Imperio Romano Germánico y pudo mantener su imperio durante 250 años más, gracias a la organización administrativa, cultural, económica, idiomática, política y, sobre todo, legislativa, de Felipe II «el Demonio del Mediodía», como le denominaron sus detractores. No obstante, la realidad es que el trabajo de este monarca excepcional, no ha sido reconocido en su justa medida, porque negligentemente se ha venido permitiendo que prevalezca la opinión crítica de sus enemigos.

Con la Nueva Recopilación, de Felipe II «el Prudente», y las Siete Partidas, de Alfonso X «el Sabio», el Derecho de Castilla se convertirá gradualmente en el Derecho Nacional para la Península Ibérica, y con las Ordenanzas sobre nuevos descubrimientos y poblaciones, elaborada para los reinos de las Indias, empezará el poblamiento de las ciudades en América. Es aquí pues, donde encontramos una característica fundamental, nunca valorada adecuadamente, en la personalidad de Felipe II: su faceta de legislador.

Recapitulando, a mi juicio, corresponde situar a Felipe II entre los legisladores del mundo, al lado del mismo emperador Justiniano. El imperio jurídico creado por Felipe II, tanto en lo que se refiere a su población, a su territorio, o a su administración, supera al creado por Justiniano. Con la Nueva recopilación estableció una técnica legal, que se utilizaría también en la Novísima recopilación, la cual, como es sabido, estuvo vigente hasta la aprobación de nuestro Código civil.

\section{BIBLIOGRAFÍA}

AA. VV. (1989). Centenario del Código Civil en el Tribunal Supremo, Madrid.

CHUECA GOITIA, Fernando (1999). El Escorial, piedra profética, Madrid. 
DE LA CUADRA BLANCO, Juan R. (1999). El Escorial y el Templo de Salomón, AA 7.

DE UNAMUNO Y JUGO, Miguel (1922). Andanzas y visiones españolas, Madrid.

ESCUDERO, José Antonio (2003). Sobre la génesis de la Nueva Recopilación, AHDE 73.

GONZÁLEZ PALENCIA, Ángel (1940). La España del siglo de oro, Madrid.

VILORIA VERA, Enrique (2010). Felipe II, el primer Globalizador, Venezuela.

THOMAS, Hugh (2010). El imperio español de Carlos V, Barcelona.

\section{CRONOLOGÍA}

1500 Nace en Gante, Carlos I de España y V de Alemania, llamado el César Carlos.

1527 Nace en Valladolid, Felipe II de España, llamado el Prudente.

1558 Muere en Yuste (Cáceres), el Emperador Carlos V.

1561 Felipe II traslada la capital de Toledo a Madrid.

1563 El 23 de abril, se coloca la primera piedra para la construcción de El Escorial.

1567 Felipe II sanciona la Nueva Recopilación.

1584 El 13 de septiembre, se coloca la última piedra construcción de El Escorial.

1598 El 13 de septiembre, muere en El Escorial, Felipe II, el Justiniano Ibérico.

\section{GLOSARIO}

Basílica: El Templo de El Escorial es un cuadrado perfecto de 50 metros y -aunque tenga bula papal o privilegio litúrgico- no es una Basílica en el sentido arquitectónico estricto.

Capilla de los Doctores: En esta capilla se encuentra un espectacular Cristo en mármol blanco de Carrara, sobre una cruz de mármol negro, de Cellini, discípulo de Miguel Angel. Originariamente, fue 
el lugar de entrada de los Profesores Doctores y los estudiantes, pero Carlos III condenó la puerta que había en el testero norte.

Capilla Mayor: Es una planta cuadrangular de 18 x 19 metros. Doce escalones de mármol nos permiten acceder al presbiterio, y cinco escalones más, a un segundo nivel, al Altar Mayor.

Enterramientos: Se denominan así a los grupos funerarios de Carlos V (lado de El Evangelio) y Felipe II (lado de La Epístola), que dejaron espacio delante y detrás, para que si alguno de sus descendientes sobrepujara las glorias de sus hazañas, o fuese mejor en virtud, ocupase este lugar. Al día de hoy, ninguno de sus descendientes se ha atrevido a ocupar este espacio.

Iglesia Vieja o de Prestado: Iglesia utilizada por Felipe II, mientras se construía El Escorial y donde tuvo su primera habitación. Su Altar está presidido por el Martirio de San Lorenzo, el cuadro más intimista oscuro y nocturno del maestro Tiziano. Parece probado que fue allí donde el monarca recibió la noticia de la derrota de la Armada Invencible.

Oratorios: Situados a ambos lados del Altar Mayor, sus paredes, suelos y bóvedas están cubiertas de diferentes colores. En concreto el lujoso Oratorio privado de Felipe II, se encuentra en el lado de la Epístola, entre el presbiterio y su dormitorio. Pequeño y falto de luz, muy apropiado para favorecer la soledad y la mística, allí, según nos cuenta el padre Sigüenza, el monarca pasaba largos ratos meditando por las noches.

Rasguño: Boceto.

Monasterio: Casa o convento, donde viven los religiosos, generalmente alejados de la ciudad.

Montea: Alzado del edificio.

Sacristía: Es la parte mejor terminada arquitectónicamente y artísticamente. Al final de siete preciosas pilastras, se encuentra un magnífico retablo presidido por el cuadro la Sagrada Forma, obra magistral de Claudio Coello, que protege la reliquia y un espléndido crucifijo de bronce dorado, de Pietro Tacca.

Sancta Sanctorum: Lugar santísimo o más sagrado del templo. Los investigadores que buscan las influencias del Templo de Salomón en El Escorial, creen que el Panteón de Reyes -de forma octogonal, de diez metros de diámetro y casi once metros de altura- es el auténtico Sancta Sanctorum de El Escorial. 
Tabernáculo: Ideado y delineado por Juan de Herrera, mide dieciséis pies por siete y medio de diámetro, fue labrado durante siete años por Jacopo Nizzola da Trezzo, a quien el monarca autorizo la construcción de la primera casa de la ciudad y con quien mantuvo una relación muy cercana. Todo El Escorial está en función del Templo y el Templo está en función del Retablo Mayor y el Retablo Mayor en su cuerpo central acoge el Tabernáculo, la obra más perfecta en su género, y que Felipe II contemplaba desde su habitación.

Templo: Edificio destinado al culto público. En el Escorial, según Sigüenza, debajo del coro se encuentra un templo pequeño y cuadrado, después el Templo como tal, y al fondo el Altar mayor.

Trazas: Dibujos.

Traza universal: Proyecto básico.

Treinta mil misas: Nada más expirar Felipe II, los numerosos altares de la Basílica celebraron hasta treinta mil misas, por la intercesión de su alma, según había dispuesto el monarca en su última voluntad. 